\title{
Treatment of SUNCT/SUNA, Paroxysmal Hemicrania, and Hemicrania Continua: An Update Including Single-Arm Meta-analyses
}

Anker Stubberud, $M D^{1,2}$

Erling Tronvik, MD, $P h D^{2,3}$

Manjit Matharu, MBChB, PhD ${ }^{1, *}$

\author{
Address \\ ${ }^{*}, 1$ Headache and Facial Pain Group, UCL Queen Square Institute of Neurology and \\ National Hospital for Neurology and Neurosurgery, Queen Square, London, WC1N \\ 3BG, UK \\ Email: m.matharu@uclmail.net \\ ${ }^{2}$ Department of Neuromedicine and Movement Sciences, NTNU Norwegian Univer- \\ sity of Science and Technology, Trondheim, Norway \\ ${ }^{3}$ Department of Neurology, St. Olavs Hospital, Trondheim, Norway
}

Published online: 11 November 2020

(C) The Author(s) 2020

This article is part of topical Collection on Headache

Keywords Paroxysmal hemicrania $\cdot$ Hemicrania continua $\cdot$ Short-lasting unilateral neuralgiform headache attacks SUNCT · Trigeminal autonomic cephalalgia

\begin{abstract}
Purpose of Review This review presents a critical appraisal of the treatment strategies for short-lasting unilateral neuralgiform headache attacks (SUNHA), paroxysmal hemicrania $(\mathrm{PH})$, and hemicrania continua $(\mathrm{HC})$. We assess the available, though sparse, evidence on both medical and surgical treatments. In addition, we present estimated pooled analyses of the most common treatments and emphasize recent promising findings.

Recent Findings The majority of literature available on the treatment of these rare trigeminal autonomic cephalalgias are small open-label observational studies and case reports. Pooled analyses reveal that lamotrigine for SUNHA and indomethacin for PH and $\mathrm{HC}$ are the preventative treatments of choice. Second-line choices include topiramate, gabapentin, and carbamazepine for SUNHA; verapamil for PH; and cyclooxygenase-2 inhibitors and gabapentin for HC. Parenteral lidocaine is highly effective as a transitional treatment for SUNHA. Novel therapeutic strategies such as non-invasive neurostimulation, targeted nerve and ganglion blockades, and invasive neurostimulation, including
\end{abstract}


implanted occipital nerve stimulators and deep brain stimulation, appears to be promising options.

Summary At present, lamotrigine as a prophylactic and parenteral lidocaine as transitional treatment remain the therapies of choice for SUNHA. While, by definition, both $\mathrm{PH}$ and $\mathrm{CH}$ respond exquisitely to indomethacin, evidence for other prophylactics is less convincing. Evidence for the novel emerging therapies is limited, though promising.

\section{Introduction}

Short-lasting unilateral neuralgiform headache attacks (SUNHA), paroxysmal hemicrania (PH), and hemicrania continua (HC) are all classified as trigeminal autonomic cephalalgias (TACs) by the International Classification of Headache Disorders [1]. TACs are mainly characterized by unilateral trigeminal distribution pain that occurs in association with ipsilateral cranial autonomic features [2]. SUNHA and PH are characterized by short-lasting intense headache attacks, with their main difference being in attack duration and frequency as well as the response to therapy. In contrast, $\mathrm{HC}$ is a continuous headache that waxes and wanes in intensity. PH and HC are characterized by absolute responsiveness to indomethacin.

These disorders are rare, but highly disabling, and management can be challenging. A plethora of pharmacological and surgical therapies has been tried, mainly in open-label observational studies and case reports. A few of these treatments emerge as being more promising than others. This review provides a short phenotypic description of these disorders (overview in Table 1), a brief description of the pathophysiology, and an update on the treatment options, including estimated weighted pooled analyses of the most commonly used treatments.

\section{Methods}

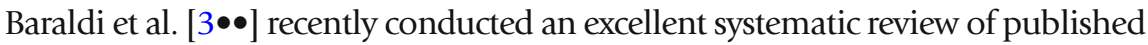
literature up to 2017. We constructed a literature base from their reference list, combined with an updated literature search. We searched MEDLINE with following three search queries from 2017 to 7 April 2020: (1) "SUNCT" OR "SUNA" OR "short lasting unilateral neuralgiform headache attacks with conjunctival injection and tearing" OR "short lasting unilateral neuralgiform headache attacks with autonomic symptoms"; (2) "paroxysmal hemicrania"; and (3) "hemicrania continua." In addition, we hand-searched the reference lists of reviews on TACs.

Treatments with two or more reports of at least five patients were included in pooled single-arm meta-analyses. Reports were not required to be controlled intervention trials as these are non-existent for these rare disorders. Studies in which a defined response to a treatment was an inclusion criterion were not considered. We calculated responder proportion with 95\% confidence intervals (CI) using a fixed-effects inverse variance model with a double arcsine transformation [4]. This model weights larger studies more than small studies and is applicable when there is no comparison group. Due to varying reporting, the respective reports' definition of clinically meaningful response was used to define treatment response. SUNCT and SUNA were considered as one entity for pooled analyses. All analyses were made using R 3.6.0 (The R Foundation for Statistical Computing) with the open-source package meta v.4.11-0. Clearly ineffective treatments used by less than five participants were not included in the review. Larger studies or studies of special interest were emphasized in more detail. 
Table 1. Clinical characteristics of short-lasting unilateral neuralgiform headache attacks, paroxysmal hemicrania, and hemicrania continua

\begin{tabular}{|c|c|c|c|}
\hline & SUNHA & $\begin{array}{l}\text { Paroxysmal } \\
\text { hemicrania }\end{array}$ & Hemicrania continua \\
\hline Sex (female:male) & $1: 1.5$ to $1: 0.58$ & $1: 1$ to $2.36: 1$ & $2: 1$ \\
\hline Age of onset & 35 to 65 & 34 to 41 & Adulthood (5 to 67) \\
\hline Laterality & Unilateral & $\begin{array}{l}\text { Strictly unilateral, } \\
\text { very rarely } \\
\text { side-shifting }\end{array}$ & $\begin{array}{l}\text { Unilateral, very rarely } \\
\text { side-shifting, or bilateral }\end{array}$ \\
\hline Quality & $\begin{array}{l}\text { Sharp, stabbing, burning, } \\
\text { or electrical shocks }\end{array}$ & $\begin{array}{l}\text { Sharp, stabbing, } \\
\text { throbbing, } \\
\text { shooting, burning, } \\
\text { or boring }\end{array}$ & $\begin{array}{l}\text { Dull, aching, or pressing; } \\
\text { but also sharp, burning, } \\
\text { aching, or stabbing }\end{array}$ \\
\hline Severity & Severe to excruciating & Excruciating & Mild to severe \\
\hline Site & $\begin{array}{l}\text { Orbital, frontal, temporal; } \\
\text { other trigeminal } \\
\text { distributions }\end{array}$ & $\begin{array}{l}\text { Orbital, frontal, and } \\
\text { temporal }\end{array}$ & $\begin{array}{l}\text { Orbital, frontal, temporal, } \\
\text { and sometimes occipital }\end{array}$ \\
\hline Attack frequency & 1 to 100 per day & 2 to 50 per day & $\begin{array}{l}\text { Fluctuating continuous } \\
\text { pain with exacerbations }\end{array}$ \\
\hline Attack duration & 1 to $600 \mathrm{~s}$ & 2 to $30 \mathrm{~min}$ & Months to years \\
\hline Cranial autonomic symptoms & $\begin{array}{l}\text { Yes. Conjunctival } \\
\text { injection and } \\
\text { lacrimation with } \\
\text { SUNCT. At least one } \\
\text { CAS, but not both } \\
\text { conjunctival injection } \\
\text { and lacrimation }\end{array}$ & Yes & Yes \\
\hline Restlessness and/or agitation & $30 \%$ & $80 \%$ & $90 \%$ \\
\hline $\begin{array}{l}\text { Migrainous features (nausea, } \\
\text { photophobia, or phonophobia) }\end{array}$ & Rare & Yes & Frequent \\
\hline Indomethacin effect & None & Absolute & Absolute \\
\hline
\end{tabular}

The literature search for SUNHA yielded 147 records. Six reports of five cohorts $[5-9,10 \bullet](n=154)$ with five or more patients were included in the pooled analyses. The literature search for $\mathrm{PH}$ yielded 40 records. Thirteen studies [11-23] $(n=189)$ with five or more patients were included in pooled analyses. The literature search for HC yielded 48 records. Ten studies [13, 17, 22-29] with a total of 131 patients were included in the pooled analyses.

\section{Pathophysiology and indomethacin response}

Currently, the most widely accepted pathophysiological construct is that an abnormality in the posterior hypothalamus leads to an activation of the trigeminal autonomic reflex-the phenomenon in which trigeminal nociceptive 
stimulation may elicit cranial parasympathetic outflow [30]. Activation of the reflex is best explained by an abnormality in the posterior hypothalamic gray matter [31], possibly via central disinhibition and a trigeminal-hypothalamic pathway [32]. This evidence stems from functional imaging studies and deep brain stimulation studies revealing activation of the posterior hypothalamus in TACs [33-36], otherwise not seen with experimentally induced forehead pain [37]. The pain is likely mediated by activation of the trigeminovascular nociceptive afferents from the peripheral cranium leading to the trigeminal nucleus caudalis (TNC) [38]. From the TNC, nociceptive pathways project to higher centers involved in pain processing, but there is also a reflex connection to the superior salivatory nucleus [39]. This reflex connection mediates the parasympathetic outflow via the sphenopalatine ganglion (SPG) and the facial nerve, explaining the autonomic symptoms [40].

The mechanism for the unique effect of indomethacin in $\mathrm{PH}$ and $\mathrm{HC}$ has not yet been clearly identified [41]. To date, the most valid theory involves nitric oxide-induced vasodilation. Indomethacin appears to inhibit the production of nitric oxide, distinguishing it from other non-steroidal anti-inflammatory drugs (NSAID), and thereby inhibit neurogenic-induced vasodilatation activating nociceptive trigeminovascular nerve fibers [42]. It is therefore believed that indomethacin may antagonize the nitric oxide pathway occurring in the parasympathetic outflow ganglia and SPG, and through this mechanism exert its effect on headache syndromes characterized by activation of the trigeminal autonomic reflex [43].

\section{Short-lasting unilateral neuralgiform headache attacks}

The first case of SUNHA was described in 1978 [44]. SUNHA is subgrouped into short-lasting unilateral neuralgiform headache attacks with conjunctival injection and tearing (SUNCT), and short-lasting unilateral neuralgiform headache attacks with autonomic symptoms (SUNA) [1]. They present with a slightly different clinical picture, but a recent large cohort suggest they should be considered the same entity [45]. Both headache syndromes are rare. One study from Australia reported the prevalence of SUNHA to be 6.6 per 100,000 [6]. The mean age of onset is estimated to 44 years (range 13-76) [45], and studies have reported both female and male preponderances $[45,46]$.

The pain in SUNCT and SUNA is unilateral, typically located in the ophthalmic area, but also maxillary and mandibular area, of the trigeminal nerve [45]. It is described as sharp, stabbing, burning, or electrical shocks [47]. The temporal profile of attacks can be categorized as one or more of the following: single stab with a duration of 1-600 s; groups of stabs with a duration of 10-200 s; or "saw-tooth" attacks of continuous pain with superimposed peaks with a duration of 5-12,000 s [45, 47]. The attack frequency is highly variable, usually 1 to 100 attacks per day (median 20 for SUNA, 30 for SUNCT) [45], but may be as high as 600 [47]. The attacks are always accompanied by ipsilateral, and sometimes 
bilateral, cranial autonomic symptoms [45]. SUNCT has to have both conjunctival injection and lacrimation, whereas SUNA occurs in association with at least one cranial autonomic symptom but not both lacrimation and conjunctival injection. In addition, one may see nasal congestion, rhinorrhea, miosis, ptosis, eyelid edema, or facial sweating/ flushing during attacks [46].

\section{Current treatment}

\section{Preventative treatment}

Lamotrigine appears to be the most effective pharmacologic prophylaxis for SUNHA. In the largest available study, comprising 102 SUNHA patients [10•], a total of 18/29 SUNCT patients and 5/16 SUNA patients reported effect of the drug. In another series $11 / 19$ patients experienced a $50 \%$ or greater reduction in headache frequency and/or severity [6]. Pooled analyses of lamotrigine in 82 patients $[6-8,10 \bullet]$ showed a responder proportion of 0.58 (95\% CI 0.47 to 0.70 ). Lamotrigine is usually started at $25 \mathrm{mg}$ daily for 2 weeks before increasing to $50 \mathrm{mg}$ daily in weeks 3 and 4 . The dose is thereafter titrated to effect and tolerance up to $400 \mathrm{mg}$ daily. Common adverse events include skin rash and nausea; serious adverse events include Steven Johnson syndrome and toxic epidermal necrolysis [48]. Lamotrigine is glucuronidated in its metabolic pathway and care must be taken if co-administering drugs that induce or inhibit glucuronidation [49].

A crossover trial of five patients reported response in two of five on topiramate and one of five on placebo [50]. In addition, an open-label study [10•] found treatment response 14/36 patients. Pooled analyses of topiramate in 42 patients $[6,10 \bullet]$ showed a responder proportion of 0.35 (95\% CI 0.20 to 0.51 ). The usual treatment regimen is to start with $15-$ $25 \mathrm{mg}$ daily and titrate up in steps of 25-50 mg to a maximum dose of $400 \mathrm{mg}$ daily.

\section{Gabapentin}

Gabapentin may also be effective as preventative treatment for SUNHA. In the largest available dataset, gabapentin was effective in $11 / 29$ SUNCT patients and in 7/18 SUNA patients [10•]. Pooled analyses of gabapentin in 63 patients $[6,9,10 \bullet]$ showed a responder proportion of 0.44 (95\% CI 0.31 to 0.57 ). The initial dose is usually $300 \mathrm{mg}$ which is increased in $300 \mathrm{mg}$ increments up to a total of $3600 \mathrm{mg}$ divided on three daily doses. The most common adverse events are dizziness and somnolence [51]. 
Carbamazepine is reported to be beneficial preventative treatment in a small proportion of SUNHA patients. In the largest study, carbamazepine was effective 20/63 patients [10•]. Pooled analyses of carbamazepine in 77 patients $[6,10 \bullet]$ showed a responder proportion of 0.29 (95\% CI 0.18 to $0.40)$.

Verapamil appears to be a poor choice as preventative treatment for

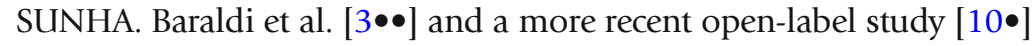
found verapamil effective in 2/6 and 2/21 patients, respectively.

Botulinum toxin

There are two case reports of positive response to botulinum toxin injections $[52,53]$. The effect of botulinum toxin should be considered uncertain until more evidence is gathered.

Non-invasive vagus nerve stimulation

A series looking at primary chronic headaches found non-invasive vagus nerve stimulation to be ineffective in the two SUNA patients included [54].

\section{Transitional treatments}

Parenteral lidocaine has been tried in several patients [6, 47], but never in controlled trials. Baraldi et al. [3••] found lidocaine to be effective in $94 \%$ of patients, and a study with 102 patients found intravenous lidocaine to be effective in 15/15 SUNCT patients and $8 / 9$ SUNA patients [10•]. Pooled analyses of lidocaine in 38 patients $[6,10 \bullet]$ showed a responder proportion of 0.91 (95\% CI 0.79 to 0.99). Lidocaine may be administered both intravenously (dose: $1.5-3.5 \mathrm{mg} / \mathrm{kg} / \mathrm{h}$ ) and subcutaneously, and there is no evidence for the superiority of either [6]. Treatment effect usually persists a few weeks, but has been observed up to 6 months [47]. Lidocaine is particularly useful as a transitional treatment for patients with statuslike attacks with frequent, easily triggered, and high intensity pain [55]. In the summary of available reports from 2017, adverse events (AE) occurred in $54 \%$ of patients [3••]. Potential AEs include depressed mood, vivid dreams, and seizures [6].

\section{Corticosteroids}

Corticosteroids, administered both perorally and intravenously, are generally less effective than lidocaine. A trial from 2017 found high-dose 
corticosteroids to be effective in $2 / 20$ patients [10•], whereas the case summaries by Baraldi et al. found prednisone effective in $6 / 11$ patients and

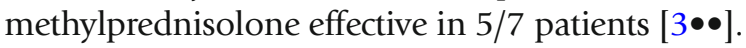

Intravenous dihydroergotamine

Intravenous dihydroergotamine administered over 5 days was ineffective in five patients [10•]. Moreover, a retrospective case review of 26 patients found a paradoxical effect with marked worsening in five patients [56].

Nerve blockades

In one case series, using lidocaine and methylprednisolone greater occipital nerve block (GONB), improvement was seen in $6 / 12$ SUNCT patients and $3 / 4$ SUNA patients [10•]. On the other hand, in a recent study, most patients had no positive effect of GONB, but multiple cranial nerve blocks (MCNB) was associated with a positive outcome in $9 / 16$ patients [57•].

\section{Surgery and invasive treatments}

Sphenopalatine ganglion procedures

SPG-pulsed radiofrequency has been attempted in nine patients in a prospective case series [58]. At 30 months follow-up, seven patients were considered responders.

Trigeminal procedures

In 2018, a summary of 19 cases, whereof ten case reports and a case series of nine patients, found that trigeminal microvascular decompression (MVD) was effective in $63 \%$ of cases at a median follow-up of 14 months [59]. In addition, a recent case report found trigeminal MVD to be effective in two patients with confirmed ipsilateral neurovascular conflict where ONS and deep brain stimulation had failed [60]. Trigeminal MVD should be considered in patients with aberrant vascular loops impinging on the ipsilateral trigeminal nerve, where medical treatments have failed.

Occipital nerve stimulation

Implantation of occipital nerve stimulators (ONS) has been performed in a study of 31 patients in which the mean daily attack frequency was reduced by $69 \%$ at median follow-up of 45 months [61•].

Deep brain stimulation

In one open-label study, 11 patients were treated with ventral tegmental area deep brain stimulation (DBS). Participants experienced a median attack frequency reduction of $78 \%$ [62]. Because of the invasiveness of the 
procedure, DBS should only be considered when all other options have failed [63].

\section{Paroxysmal hemicrania}

PH was first described by Sjaastad and Dale in 1974 [64] and entitled "chronic paroxysmal hemicrania" a few years later. The exact incidence and prevalence is not known. Some authors suggest a prevalence equal to $1-3 \%$ of cluster headache [65], corresponding to an overall prevalence of 1 per 25,000. Several studies have found a female preponderance $[18,65]$. However, a more recent prospective study found a sex ratio of 1:1 [15]. The mean age of onset ranges from 34 to 41 years $[15,18,65]$.

\section{Diagnostic evaluation}

The pain in PH is strictly unilateral and without side shift in more than $95 \%$ of cases [15]. The pain is usually ophthalmic trigeminal distributed and described as sharp, stabbing, throbbing, shooting, burning, or boring [15]. The attack duration is usually $2-30$ min (range $2-120$ ), with an estimated daily mean attack frequency of 6 to 14 (range 2-50) [15, 18, 65, 66]. PH may be episodic or chronic, where the chronic form has no remission periods for at least a year, or the remission periods last less than 3 months [1]. The attacks are typically associated with ipsilateral cranial autonomic features, where lacrimation, conjunctival injection, rhinorrhea, nasal congestion, ptosis, and facial flushing are the most common [15]. Attacks are often associated with agitation or restlessness $[15,65]$. A trial of oral indomethacin, as described below, should be initiated to confirm the diagnosis. Alternatively, an intramuscular "indotest" may establish the diagnosis faster [22].

Current treatment

Abortive treatment

Sumatriptan

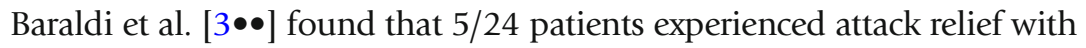
sumatriptan. Pooled analysis of three studies $[13,15,19]$ with a total of 26 patients showed a responder proportion of 0.13 (95\% CI 0.01 to 0.30 ).

\section{Preventative treatment}

By definition, PH responds to indomethacin [1]. There are, however, reports of patients with clinical symptoms consistent with $\mathrm{PH}$ where indomethacin is not effective $[18,67]$. In the largest prospective study of $31 \mathrm{PH}$ patients, 30 could tolerate indomethacin and all had an effect [15]. On the 
other hand, a retrospective study of likely $\mathrm{PH}$ cases found a consistent response to indomethacin in 30/40 patients [18]. In the latter, it should be noted that several of the patients with an inconsistent response did not strictly meet PH criteria. Our pooled analyses of indomethacin in 135 patients $[11,12,14-19,22]$ showed a responder proportion of 0.97 (95\% CI 0.93 to 1.00). Of note, this analysis includes the study with 30/40 responders, lump adults, and children, and includes studies where an inclusion criterion was response to indomethacin. The starting dose for indomethacin is $75 \mathrm{mg}$ daily in three divided doses. Onset of effect is usually prompt, occurring within 1 to 2 days of administering the effective dose. The dose is increased to $150 \mathrm{mg}$ divided by three daily doses after 3 days in the absence of response. This dose should be continued for up to 10 days as we have observed a patient that required 10 days to respond completely. The dose should be further increased to $225 \mathrm{mg}$, or even $300 \mathrm{mg}$ daily, in three divided doses in cases of partial response or high suspicion. In the absence of response, the diagnosis should be reconsidered. The maintenance dose of indomethacin is usually 25 to $100 \mathrm{mg}$ daily but may be as high as $300 \mathrm{mg}$ daily. Cases that require escalating doses or become refractory should raise suspicion of a secondary cause [68]. Adverse events are the same as for commonly used NSAIDs, and approximately $25 \%$ of $\mathrm{PH}$ patient on indomethacin seems to develop gastrointestinal side effects [17].

Other non-steroidal anti-inflammatory drugs

Several other NSAIDs including aspirin [19, 65, 69], ibuprofen [19], naproxen [19, 70-72], diclofenac [19, 73], ketoprofen [65], and piroxicam [74] have been tried in case reports. However, none of these display the same consistent and absolute effect as indomethacin. In addition, there are some reports of effect with cyclooxygenase-2 (COX-2) inhibitors [75-77], but several of these are associated with increased risk of ischemic cardiovascular disease and should be prescribed with great caution.

Verapamil

Verapamil is generally considered the best alternative when treatment with indomethacin is not possible. Baraldi et al. found verapamil to be effective

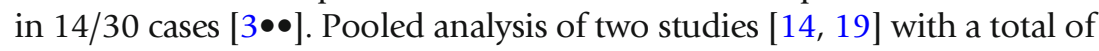
16 patients showed a responder proportion of 0.44 (95\% CI 0.19 to 0.70 ). Verapamil is usually started in doses of 160 to $240 \mathrm{mg}$ and titrated up as needed and tolerated to $960 \mathrm{mg}$ daily. Of note, other calcium channel antagonists, including flunarizine and nicardipine, have also been reported to be effective for PH $[19,78]$. 
Carbamazepine

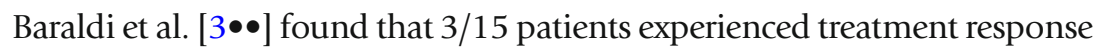
on carbamazepine.

Non-invasive vagus nerve stimulation

Percutaneous vagus nerve stimulation has been reported to be effective in observational studies $[20 \bullet, 21 \bullet]$. In the first study, 4/6 PH patient reported a treatment benefit. In the second study, treatment response was observed in $6 / 8$ patients and the mean monthly headache frequency was reduced by $75 \%$ at

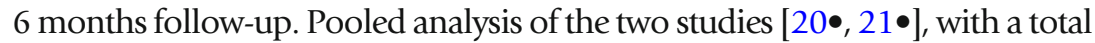
of 14 patients, showed a responder proportion of 0.72 ( $95 \%$ CI 0.43 to 0.94 ).

\section{Transitional treatment}

Nerve blockades

Local anesthetic blockade with lidocaine of the greater occipital nerve, supraorbital nerve, and lesser occipital nerve have generally been ineffective $[23,57 \bullet, 79]$. However, two cases of complete response to GONB [80] and repeated C7 sympathetic chain block [81] has been reported. The latter became pain-free after a stellate ganglionectomy. In a larger series of different chronic headaches that had failed GONB, response to MCNB was seen in $1 / 4 \mathrm{PH}$ patients [57•].

\section{Surgery and invasive treatments}

Surgical procedures, including infraorbital nerve section, superficial petrosal nerve section, trigeminal root section, and SPG ganglionectomy, have largely been ineffective $[65,81]$. However, there are case reports of effective surgical treatment with occipital nerve stimulation [82 $\bullet$, posterior hypothalamic DBS [83], and the above-mentioned stellate ganglionectomy [81].

\section{Hemicrania continua}

HC was likely first described by Diamond and Medina in 1981 [84], but the term "hemicrania continua" was coined by Sjaastad and colleagues 3 years later [85]. Since then, over thousand cases have been reported. The true prevalence is unknown. Though originally believed to be rare, some research suggests that HC is more common than suspected, with identification of large number of cases at single sites within a few years [86]. HC appears to have a female preponderance, with a female-to-male ratio of 2:1, and the typical age of onset is in adulthood (range 5-67) [86].

HC is characterized by a continuous unilateral headache, associated with cranial autonomic symptoms, restlessness during exacerbations, and responsiveness to indomethacin. Most patients with HC has unremitting pain, but up to $20 \%$ of 
cases have pain-free periods from 1 day to several months [26]. The pain is usually side-locked unilateral, but there are cases of alternating sides [26, 87], and even bilateral pain [88]. The pain is typically located around the orbit, frontal region, and temporal region, but also occipital and neck pain has been described $[26,89]$. The continuous pain fluctuates in intensity and is superimposed by severe attacks. These attacks usually last from minutes to several days. During the exacerbations, there are usually associated cranial autonomic symptoms [90]. Similarly to PH, the diagnosis should be confirmed with a trial of oral indomethacin or the "indotest."

\section{Current treatment}

\section{Abortive treatment}

Sumatriptan

Two studies [13, 26] of 7 and 25 patients, respectively, had no responders on sumatriptan. Pooled analyses of the two studies resulted in a responder proportion of 0.00 ( $95 \%$ CI 0.00 to 0.05 ).

\section{Preventative treatment}

\section{Indomethacin}

Similar to PH, HC responds, by definition, to indomethacin. Baraldi et al. [3••] found indomethacin to be effective in 157/159 patients. These findings are mainly based on case reports and case series, but a few larger studies have been conducted. Three reports of 11,16, and 39 patients respectively, showed a treatment response in all patients on indomethacin [17, 26, 27]. In the first series, all patients experienced pain relief within $24 \mathrm{~h}$ at doses $25-$ $150 \mathrm{mg}$ [27]. In the second series, the mean effective dose was $78 \mathrm{mg}$ [17]. Pooled analysis of four studies [17, 24, 26, 27] with a total of 82 participants showed a responder proportion of 1.0 (95\% CI 0.98 to 1.00). After achieving headache relief, it is often advisable to find the lowest maintenance dose [17, 27]. This will lower discontinuation rate due to intolerance. As for $\mathrm{PH}$, there are reports on cases of $\mathrm{HC}$ that are indomethacin-insensitive [91, 92]. Adverse events and treatment precautions are the same as discussed for $\mathrm{PH}$.

In a case series of 14 patients, 6 responded completely to COX-2 [29]. In another larger clinical study, only 2/14 participants using COX-2 inhibitors had a response. Another case series of four patients found complete response to celecoxib in all [93]. In addition, there are both positive [94] and negative [95] case reports. Pooled analysis of two studies [26, 29] with a total of 28 patients showed a responder proportion of 0.28 (95\% CI 0.12 to 0.46 ). Likewise, as for $\mathrm{PH}$, long-term use of COX-2 inhibitors is associated with increased risk of ischemic cardiovascular disease and should be prescribed with great caution. 
Baraldi et al. [3••] found response on gabapentin in 11/13 patients. However, our pooled analysis of two studies $[25,26]$ with a total of 22 patients showed a responder proportion of 0.22 ( $95 \% \mathrm{CI} 0.06$ to 0.43 ). It should be

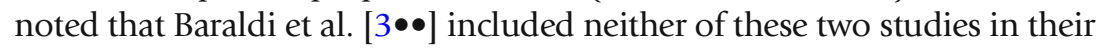
summary of gabapentin.

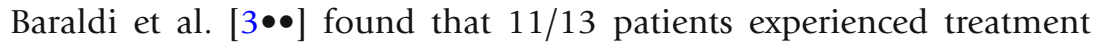
response on topiramate. Moreover, a case report of two patients from 2019 suggests that topiramate may have an indomethacinsparing effect [96].

Verapamil

Baraldi et al. $[3 \bullet \bullet]$ found that $3 / 8$ patients experienced treatment response on verapamil.

Melatonin

Baraldi et al. [3••] found that 9/17 patients experienced treatment response on melatonin.

Botulinum toxin

In a case series of nine patients treated with botulinum toxin, five patients demonstrated a $50 \%$ or more reduction in moderate to severe headache days [97]. The median duration of response was 11 weeks.

Non-invasive vagus nerve stimulation

In a retrospective series of seven HC patients, non-invasive vagus nerve stimulation provided reduction in severity of continuous pain in all patients, and reduction in exacerbation intensity in two patients $[20 \bullet]$.

\section{Transitional treatment}

There are several reports of extracranial nerve blockades in HC. A series of seven HC patients found reduction in pain intensity with superior orbital nerve blockades (SONB) with lidocaine [23], but no pain relief for any of the patients with GONB. In another study, nine patients with palpation tenderness over the greater occipital nerve, superior orbital nerve, or trochlear area were treated with one or more blockades to the tender areas, and complete pain relief was found in five patients and partial relief in four patients. Finally, a 
larger series including six HC patients, who all had failed GONB, found a good response to MCNB in five patients [57]. Pooled analyses of two studies [23, 26] with a total of 30 participants showed a responder proportion on GONB of 0.23 (95\% CI 0.09 to 0.41 , while pooled analyses of two studies [23, 28] with a total of 13 participants showed a responder proportion on SONB of 0.83 (95\% CI 0.55 to 1.00). At present MCNB and SONB seems to be superior to GONB, but findings must be confirmed in larger trials.

\section{Surgery and invasive treatments}

Supraorbital nerve radiofrequency ablation

Radiofrequency ablation of the superior orbital nerve has been effective in a case series of three patients [98].

Sphenopalatine ganglion procedures

In a case report, repetitive SPG block with bupivacaine was effective [99].

SPG radiofrequency ablation was also effective in another case report [100].

Occipital nerve stimulation

In a series of 16 patients with implanted bilateral ONS, a mean monthly reduction in moderate-to-severe headache by $48.9 \%$ was observed [101]. ONS has also been found to be effective in 2/2 [102], 6/6 [103], and 2/4 patients [54] in case series and open-label studies.

\section{Conclusion}

SUNHA, PH, and HC are rare headache syndromes that can be difficult to diagnose and treat correctly. All the reviewed treatments are summarized in Table 2. At present, SUNHA should preferably be treated with lamotrigine as a prophylactic, while topiramate, gabapentin, and carbamazepine are reasonable secondary options. Parenteral lidocaine is useful when a transitional treatment is required. Invasive therapies such as ONS, trigeminal surgical procedures, and ventral tegmental area DBS are promising options for refractory patients. $\mathrm{PH}$ and $\mathrm{HC}$ can usually be readily treated with indomethacin when tolerated, but some patients will require other treatments. Even though there is a scarcity of other effective preventatives, verapamil may be tried in PH and COX-2 inhibitors and gabapentin may be tried in HC. Peripheral cranial nerve blockades are often ineffective, except for SONB and MCNB in HC. In addition, non-invasive vagus nerve stimulation is emerging as a promising and readily accessible prophylactic for both PH and HC. Finally, a 
Table 2. Overview of reviewed treatments for SUNHA, PH, and CH

\begin{tabular}{|c|c|c|c|}
\hline & Treatment & $\begin{array}{l}\text { Pooled weighted } \\
\text { responder proportion } \\
(95 \% \mathrm{CI})\end{array}$ & Comment \\
\hline \multicolumn{4}{|c|}{ 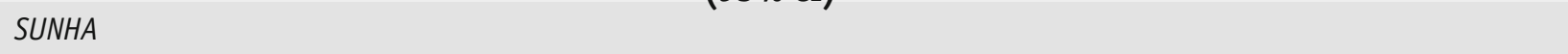 } \\
\hline \multicolumn{4}{|l|}{ Abortive treatments } \\
\hline & - & - & $\begin{array}{l}\text { Abortive treatment not feasible for } \\
\text { the short attacks of SUNHA. }\end{array}$ \\
\hline \multicolumn{4}{|c|}{ Preventative treatments } \\
\hline \multirow[t]{5}{*}{ Oral } & Lamotrigine & $0.58(0.47$ to 0.70$)$ & $\begin{array}{l}\text { Should be considered first-line pre- } \\
\text { ventative treatment. }\end{array}$ \\
\hline & Topiramate & 0.35 (0.20 to 0.51$)$ & $\begin{array}{l}\text { Variable effect in case reports and } \\
\text { observational studies. }\end{array}$ \\
\hline & Gabapentin & $0.44(0.31$ to 0.57$)$ & $\begin{array}{l}\text { Variable effect in case reports and } \\
\text { observational studies. }\end{array}$ \\
\hline & Carbamazepine & $0.29(0.18$ to 0.40$)$ & $\begin{array}{l}\text { Variable effect in case reports and } \\
\text { observational studies. }\end{array}$ \\
\hline & Verapamil & - & $\begin{array}{l}\text { Rarely effective in case reports and } \\
\text { observational studies. }\end{array}$ \\
\hline Injectable & Botulinum toxin & - & Effective in a few case reports. \\
\hline $\begin{array}{l}\text { Non-invasive } \\
\text { neurostimulation }\end{array}$ & $\begin{array}{l}\text { Vagus nerve } \\
\text { stimulation }\end{array}$ & - & $\begin{array}{l}\text { Ineffective in on observational } \\
\text { study. }\end{array}$ \\
\hline \multicolumn{4}{|c|}{ Transitional treatments } \\
\hline & Parenteral lidocaine & 0.91 (0.79 to 0.99$)$ & $\begin{array}{l}\text { Should be considered first-line tran- } \\
\text { sitional treatment. }\end{array}$ \\
\hline & Corticosteroids & - & $\begin{array}{l}\text { Rarely effective in case reports and } \\
\text { observational studies. }\end{array}$ \\
\hline & GONB & - & $\begin{array}{l}\text { Variable effect in case reports and } \\
\text { observational studies. }\end{array}$ \\
\hline & MCNB & - & $\begin{array}{l}\text { Variable effect in case reports and } \\
\text { observational studies. }\end{array}$ \\
\hline \multicolumn{4}{|l|}{$\begin{array}{l}\text { Paradoxical effect with } \\
\text { worsening in several } \\
\text { patients. }\end{array}$} \\
\hline \multirow[t]{4}{*}{ Invasive treatments } & ONS & - & $\begin{array}{l}\text { Promising effect in one } \\
\text { observational study. }\end{array}$ \\
\hline & $\begin{array}{l}\text { SPG pulsed } \\
\text { radiofrequency }\end{array}$ & - & $\begin{array}{l}\text { Promising effect in one prospective } \\
\text { study. }\end{array}$ \\
\hline & $\begin{array}{l}\text { Trigeminal } \\
\text { microvascular } \\
\text { decompression }\end{array}$ & - & $\begin{array}{l}\text { Effective in patients with confirmed } \\
\text { trigemino-neurovascular conflict. }\end{array}$ \\
\hline & $\begin{array}{l}\text { Ventral tegmental } \\
\text { area DBS }\end{array}$ & - & $\begin{array}{l}\text { Promising effect in one } \\
\text { observational study. }\end{array}$ \\
\hline
\end{tabular}


Table 2. (Continued)

\section{Treatment}

\section{Paroxysmal hemicrania}

Abortive treatments

Preventative treatments

Oral

-invasive

neurostimulation

Transitional treatments

$$
\begin{aligned}
& \text { GONB } \\
& \text { MCNB }
\end{aligned}
$$

Invasive treatments

$$
\begin{aligned}
& \text { ONS } \\
& \text { Ventral tegmental } \\
& \text { DBS }
\end{aligned}
$$

\section{Hemicrania continua}

Abortive treatments

$$
\text { Sumatriptan }
$$

Preventative treatments

Oral

Indomethacin
COX-2 inhibitors
Gabapentin
Topiramate
Verapamil
Melatonin

\section{Pooled weighted responder proportion (95\% CI)}

0.10 (0.00 to 0.34$)$.

0.97 (0.92 to 1.00$)$.

$-$

0.44 (0.19 to 0.70$)$.

$0.72(0.43$ to 0.94$)$ stimulation

0.00 (0.00 to 0.05$)$.

1.00 (0.98 to 1.00$)$

0.28 ( 0.12 to 0.46$)$

0.22 (0.06 to 0.43$)$

\section{Comment}

Appears to be largely ineffective.

Effective. First-line treatment.

Generally, less effective than indomethacin.

Variable effect in case reports and observational studies.

Variable effect in case reports and observational studies.

Rarely effective in case reports and observational studies.

Promising effect in two observational studies.

Appears to be largely ineffective.

Appears to be largely ineffective.

Promising effect in one observational study.

Promising effect in one observational study.

Appears to be largely ineffective.

Effective. First-line treatment.

Generally, less effective than indomethacin.

Rarely effective in case reports and observational studies.

Variable effect in case reports and observational studies.

Rarely effective in case reports and observational studies.

Variable effect in case reports and observational studies. 
Table 2. (Continued)

\begin{tabular}{|c|c|c|c|}
\hline & Treatment & $\begin{array}{l}\text { Pooled weighted } \\
\text { responder proportion } \\
(95 \% \mathrm{CI})\end{array}$ & Comment \\
\hline Injectable & Botulinum toxin & - & $\begin{array}{l}\text { Promising effect in one } \\
\text { observational study. }\end{array}$ \\
\hline $\begin{array}{l}\text { Non-invasive } \\
\text { neurostimulation }\end{array}$ & $\begin{array}{l}\text { Vagus nerve } \\
\text { stimulation }\end{array}$ & - & $\begin{array}{l}\text { Promising effect in one } \\
\text { observational study. }\end{array}$ \\
\hline \multicolumn{4}{|c|}{ Transitional treatments } \\
\hline & GONB & $0.23(0.09$ to 0.41$)$ & $\begin{array}{l}\text { Rarely effective in case reports and } \\
\text { observational studies. }\end{array}$ \\
\hline & SONB & 0.83 (0.55 to 1.00$)$ & $\begin{array}{l}\text { Largely effective in case reports and } \\
\text { observational studies. }\end{array}$ \\
\hline & MCNB & - & $\begin{array}{l}\text { Variable effect in case reports and } \\
\text { observational studies. }\end{array}$ \\
\hline \multirow[t]{3}{*}{ Invasive treatments } & $\begin{array}{l}\text { SON radiofrequency } \\
\text { ablation }\end{array}$ & - & Effective in one case series. \\
\hline & SPG procedures & - & Effective in two case reports. \\
\hline & ONS & - & $\begin{array}{l}\text { Variable effect in case reports and } \\
\text { observational studies. }\end{array}$ \\
\hline \multicolumn{4}{|c|}{$\begin{array}{l}\text { Pooled weighted responder proportions with } 95 \% \text { confidence intervals }(C I) \text { are provided for treatments with more than two reports of at least } \\
\text { five patients available. GONB, greater occipital nerve blockade; } M C N B \text {, multiple cranial nerve blockades; ONS, occipital nerve stimulator; SPG, } \\
\text { sphenopalatine ganglion; DBS, deep brain stimulation; NSAID, non-steroidal anti-inflammatory drugs; COX-2, cyclooxygenase-2; SONB, } \\
\text { supraorbital nerve blockade; SON, supraorbital nerve }\end{array}$} \\
\hline
\end{tabular}

subset of PH and HC patients may benefit from ONS or invasive SPG procedures.

\section{Compliance with Ethical Standards}

\section{Conflict of Interest}

Dr. Matharu reports grants and other funding from Abbott, Medtronic, Autonomic technologies, Allergan, TEVA, Novartis, Eli Lilly, and electroCore outside the submitted work. In addition, Dr. Matharu has issued a patent for his system and method for diagnosing and treating headaches. Dr. Stubberud is a co-founder and shareholder of Nordic Brain Tech, a company developing a non-pharmacological biofeedback treatment for migraines and he holds a pending patent application relating to the company's product. Dr. Tronvik reports funds from a Nordic BrainTech shareholder, a Palion Medical shareholder, and personal fees from Advisory Boards TEVA, Allergan, Novartis, and Eli Lilly. Funds are also reported from Speaker honoraria TEVA, Novartis, and Eli Lilly outside the submitted work.

\section{Human and Animal Rights and Informed Consent}

All reported studies/experiments with human or animal subjects performed by the authors have been previously published and complied with all applicable ethical standards (including the Helsinki 
declaration and its amendments, institutional/national research committee standards, and international/ national/institutional guidelines).

\section{Open Access}

This article is licensed under a Creative Commons Attribution 4.0 International License, which permits use, sharing, adaptation, distribution and reproduction in any medium or format, as long as you give appropriate credit to the original author(s) and the source, provide a link to the Creative Commons licence, and indicate if changes were made. The images or other third party material in this article are included in the article's Creative Commons licence, unless indicated otherwise in a credit line to the material. If material is not included in the article's Creative Commons licence and your intended use is not permitted by statutory regulation or exceeds the permitted use, you will need to obtain permission directly from the copyright holder. To view a copy of this licence, visit http://creativecommons.org/licenses/by/4.0/.

\section{References and Recommended Reading}

Papers of particular interest, published recently, have been highlighted as:

- Of importance

$\bullet \quad$ Of major importance

1. Headache Classification Committee of the International Headache Society (IHS). The international classification of headache disorders, 3rd edition. Cephalalgia. 2018;38(1):1-211. https://doi.org/10. $1177 / 0333102417738202$.

2. Goadsby PJ, Lipton RB. A review of paroxysmal hemicranias, SUNCT syndrome and other shortlasting headaches with autonomic feature, including new cases. Brain J Neurol. 1997;120(1):193209.

3.• Baraldi C, Pellesi L, Guerzoni S, Cainazzo MM, Pini LA Therapeutical approaches to paroxysmal hemicrania, hemicrania continua and short lasting unilateral neuralgiform headache attacks: a critical appraisal. J Headache Pain. 2017;18(1):71

A critical review that effectively summarizes almost all published literature on the treatment of SUNHA, PH and CH up to 2017.

4. Barendregt JJ, Doi SA, Lee YY, Norman RE, Vos T. Metaanalysis of prevalence. J Epidemiol Community Health. 2013;67(11):974-8.

5. Cohen AS. Short-lasting unilateral neuralgiform headache attacks with conjunctival injection and tearing. Cephalalgia. 2007;27(7):824-32. https://doi.org/10 1111/j.1468-2982.2007.01352.x.

6. Williams MH, Broadley SA. SUNCT and SUNA: clinical features and medical treatment. J Clin Neurosci. 2008;15(5):526-34. https://doi.org/10.1016/j.jocn. 2006.09.006.

7. D'Andrea G, Granella F, Ghiotto N, Nappi G. Lamotrigine in the treatment of SUNCT syndrome. Neurology. 2001;57(9):1723-5.

8. Cação G, Correia FD, Pereira-Monteiro J. SUNCT syndrome: a cohort of 15 Portuguese patients. Cephalalgia. 2016;36(10):1002-6.
9. Etemadifar M, Maghzi A, Ghasemi M, Chitsaz A, Esfahani MK. Efficacy of gabapentin in the treatment of SUNCT syndrome. Cephalalgia. 2008;28(12):133942.

10. Weng H-Y, Cohen AS, Schankin C, Goadsby PJ. Phenotypic and treatment outcome data on SUNCT and SUNA, including a randomised placebo-controlled trial. Cephalalgia. 2017;38(9):1554-63. https://doi.org/ $10.1177 / 0333102417739304$

A clinical description of 102 SUNCT and SUNA patients with both phenotypical descriptions and summary of attempted treatments.

11. Benoliel R, Sharav Y. Paroxysmal hemicrania: case studies and review of the literature. Oral Surg Oral Med Oral Pathol Oral Radiol Endod. 1998;85(3):285-92.

12. Blankenburg M, Hechler T, Dubbel G, Wamsler C, Zernikow B. Paroxysmal hemicrania in children-symptoms, diagnostic criteria, therapy and outcome. Cephalalgia. 2009;29(8):873-82.

13. Antonaci F, Pareja JA, Caminero AB, Sjaastad O. Chronic paroxysmal hemicrania and hemicrania continua: lack of efficacy of sumatriptan. Headache: The Journal of Head and Face Pain. 1998;38(3):197-200.

14. Zidverc-Trajkovic J, Pavlovic A, Mijajlovic M, Jovanovic Z, Sternic N, Kostic V. Cluster headache and paroxysmal hemicrania: differential diagnosis. Cephalalgia. 2005;25(4):244-8.

15. Cittadini E, Matharu MS, Goadsby PJ. Paroxysmal hemicrania: a prospective clinical study of 31 cases. Brain. 2008;131(Pt 4):1142-55. https://doi.org/10. 1093/brain/awn010.

16. Prakash S, Belani P, Susvirkar A, Trivedi A, Ahuja S, Patel A. Paroxysmal hemicrania: a retrospective study of a consecutive series of 22 patients and a critical 
analysis of the diagnostic criteria. J Headache Pain. 2013;14(1):26.

17. Pareja JA, Caminero AB, Franco E, Casado JL, Pascual J, Dose Sanchez del Rio M. Efficacy and tolerability of long-term indomethacin treatment of chronic paroxysmal hemicrania and hemicrania continua. Cephalalgia. 2001;21(9):906-10. https://doi.org/10. 1046/j.1468-2982.2001.00287.x.

18. Boes CJ, Dodick DW. Refining the clinical spectrum of chronic paroxysmal hemicrania: a review of 74 patients. Headache. 2002;42(8):699-708. https://doi. org/10.1046/j.1526-4610.2002.02171.x.

19. Evers S, Husstedt IW. Alternatives in drug treatment of chronic paroxysmal hemicrania. Headache. 1996;36(7):429-32. https://doi.org/10.1046/j.15264610.1996.3607429.x.

20.• Tso AR, Marin J, Goadsby PJ. Noninvasive vagus nerve stimulation for treatment of indomethacinsensitive headaches. JAMA Neurol. 2017;74(10):1266-7. https://doi.org/10.1001/ jamaneurol.2017.2122

The first larger study describing treatment of $\mathrm{PH}$ and $\mathrm{CH}$ with non-invasive vagus nerve stimulation.

21. Kamourieh S, Lagrata S, Matharu MS. Non-invasive vagus nerve stimulation is beneficial in chronic paroxysmal hemicrania. J Neurol Neurosurg Psychiatry. 2019;90(9):1072-4. https://doi.org/10.1136/jnnp2018-319538

A recent larger study describing treatment of $\mathrm{PH}$ with noninvasive vagus nerve stimulation.

22. Antonaci F, Pareja JA, Caminero AB, Sjaastad O. Chronic paroxysmal hemicrania and hemicrania continua. Parenteral indomethacin: the 'indotest'. Headache. 1998;38(2):122-8. https://doi.org/10.1046/j. 1526-4610.1998.3802122.x.

23. Antonaci F, Pareja JA, Caminero AB, Sjaastad O. Chronic paroxysmal hemicrania and hemicrania continua: anaesthetic blockades of pericranial nerves. Funct Neurol. 1997;12(1):11-5.

24. Hryvenko I, Cervantes-Chavarría AR, Law AS, Nixdorf DR. Hemicrania continua: case series presenting in an orofacial pain clinic. Cephalalgia. 2018;38(13):1950_ 9.

25. Spears RC. Is gabapentin an effective treatment choice for hemicrania continua? J Headache Pain. 2009;10(4):271-5.

26. Cittadini E, Goadsby PJ. Hemicrania continua: a clinical study of 39 patients with diagnostic implications. Brain. 2010;133(Pt 7):1973-86. https://doi.org/10. 1093/brain/awq137.

27. Pareja JA, Sjaastad O. Chronic paroxysmal hemicrania and hemicrania continua. Interval between indomethacin administration and response. Headache: The Journal of Head and Face Pain. 1996;36(1):20-3.

28. Guerrero AL, Herrero-Velázquez S, Penas ML, Mulero P, Pedraza MI, Cortijo E, et al. Peripheral nerve blocks: a therapeutic alternative for hemicrania continua. Cephalalgia. 2012;32(6):505-8.
29. Peres MF, Silberstein SD. Hemicrania continua responds to cyclooxygenase-2 inhibitors. Headache. 2002;42(6):530-1. https://doi.org/10.1046/j.15264610.2002.02131.x.

30. Akerman S, Holland PR, Summ O, Lasalandra MP, Goadsby PJ. A translational in vivo model of trigeminal autonomic cephalalgias: therapeutic characterization. Brain. 2012;135(Pt 12):3664-75. https://doi.org/10. 1093/brain/aws249.

31. Leone M, Bussone G. Pathophysiology of trigeminal autonomic cephalalgias. Lancet Neurol. 2009;8(8):755-64. https://doi.org/10.1016/s14744422(09)70133-4.

32. Malick A, Strassman RM, Burstein R. Trigeminohypothalamic and reticulohypothalamic tract neurons in the upper cervical spinal cord and caudal medulla of the rat. J Neurophysiol. 2000;84(4):2078-112. https://doi.org/10.1152/jn. 2000.84.4.2078.

33. Matharu MS, Cohen AS, Frackowiak RS, Goadsby PJ. Posterior hypothalamic activation in paroxysmal hemicrania. Ann Neurol. 2006;59(3):535-45. https:// doi.org/10.1002/ana.20763.

34. Matharu MS, Cohen AS, McGonigle DJ, Ward N, Frackowiak RS, Goadsby PJ. Posterior hypothalamic and brainstem activation in hemicrania continua. Headache: The Journal of Head and Face Pain. 2004;44(8):747-61.

35. Sprenger T, Valet M, Platzer S, Pfaffenrath V, Steude U, Tolle TR. SUNCT: bilateral hypothalamic activation during headache attacks and resolving of symptoms after trigeminal decompression. Pain. 2005;113(3):422-6. https://doi.org/10.1016/j.pain. 2004.09.021.

36. Akram H, Miller S, Lagrata S, Hariz M, Ashburner J, Behrens $\mathrm{T}$, et al. Optimal deep brain stimulation site and target connectivity for chronic cluster headache. Neurology. 2017;89(20):2083-91. https://doi.org/10. 1212/wnl.0000000000004646.

37. May A, Kaube H, Büchel C, Eichten C, Rijntjes M, Jüptner $M$, et al. Experimental cranial pain elicited by capsaicin: a PET study. Pain. 1998;74(1):61-6.

38. Hoskin KL, Zagami AS, Goadsby PJ. Stimulation of the middle meningeal artery leads to Fos expression in the trigeminocervical nucleus: a comparative study of monkey and cat. J Anat. 1999;194(4):579-88.

39. Knight YE, Classey JD, Lasalandra MP, Akerman S, Kowacs F, Hoskin KL, et al. Patterns of fos expression in the rostral medulla and caudal pons evoked by noxious craniovascular stimulation and periaqueductal gray stimulation in the cat. Brain Res. 2005;1045(12):1-11.

40. Goadsby PJ, Edvinsson L. Human in vivo evidence for trigeminovascular activation in cluster headache neuropeptide changes and effects of acute attacks therapies. Brain. 1994;117(3):427-34.

41. Summ O, Evers S. Mechanism of action of indomethacin in indomethacin-responsive headaches. Curr Pain Headache Rep. 2013;17(4):327. 
42. Summ O, Andreou AP, Akerman S, Goadsby PJ. A potential nitrergic mechanism of action for indomethacin, but not of other COX inhibitors: relevance to indomethacin-sensitive headaches. J Headache Pain. 2010;11(6):477-83. https://doi.org/10.1007/s10194010-0263-7.

43. Goadsby PJ, Uddman R, Edvinsson L. Cerebral vasodilatation in the cat involves nitric oxide from parasympathetic nerves. Brain Res. 1996;707(1):110-8. https://doi.org/10.1016/0006-8993(95)01206-0.

44. Sjaastad O, Russell D, Horven I, Bunaes U. Multiple neuralgiform unilateral headache attacks associated with conjunctival injection and appearing in clusters. A nosological problem. Proc Scand Migraine Soc 1978. p. 31.

45. Lambru G, Rantell K, Levy A, Matharu MS. A prospective comparative study and analysis of predictors of SUNA and SUNCT. Neurology. 2019;93(12):e1127e37. https://doi.org/10.1212/wnl.

0000000000008134

46. Favoni V, Grimaldi D, Pierangeli G, Cortelli P, Cevoli S. SUNCT/SUNA and neurovascular compression: new cases and critical literature review. Cephalalgia. 2013;33(16):1337-48. https://doi.org/10.1177/ 0333102413494273.

47. Cohen AS, Matharu MS, Goadsby PJ. Short-lasting unilateral neuralgiform headache attacks with conjunctival injection and tearing (SUNCT) or cranial autonomic features (SUNA)-a prospective clinical study of SUNCT and SUNA. Brain. 2006;129(Pt 10):274660. https://doi.org/10.1093/brain/awl202.

48. Parker G. Risks associated with lamotrigine prescription: a review and personal observations. Australas Psychiatry. 2018;26(6):640-2. https://doi.org/10. 1177/1039856218760733.

49. Burstein AH. Lamotrigine. Pharmacotherapy. 1995;15(2):129-43.

50. Cohen A, Goadsby P, Matharu M. Double-blind placebo-controlled trial of topiramate in SUNCT.

Cephalalgia: BLACKWELL PUBLISHING; 2007. p. 758.

51. Linde M, Mulleners WM, Chronicle EP, McCrory DC. Gabapentin or pregabalin for the prophylaxis of episodic migraine in adults. Cochrane Database Syst Rev. 2013;6:Cd010609. https://doi.org/10.1002/ 14651858.cd010609.

52. Zhang Y, Zhang H, Lian Y-J, Ma Y-Q, Xie N-C, Cheng X, et al. Botulinum toxin a for the treatment of a child with SUNCT syndrome. Pain Res Manag. 2016;2016:1-4.

53. Zabalza RJ. Sustained response to botulinum toxin in SUNCT syndrome. Cephalalgia. 2012;32(11):869-72.

54. Trimboli M, Al-Kaisy A, Andreou AP, Murphy M, Lambru G. Non-invasive vagus nerve stimulation for the management of refractory primary chronic headaches: a real-world experience. Cephalalgia.

2018;38(7):1276-85. https://doi.org/10.1177/ 0333102417731349 .

55. Montes E, Alberca R, Lozano P, Franco E, MartinezFernandez E, Mir P. Statuslike SUNCT in two young women. Headache. 2001;41(8):826-9. https://doi. org/10.1046/j.1526-4610.2001.01151.x.

56. Lambru G, Shanahan P, Matharu M. Exacerbation of SUNCT and SUNA syndromes during intravenous dihydroergotamine treatment: a case series. Cephalalgia. 2015;35(12):1115-24. https://doi.org/10.1177/ 0333102415570495.

57. Miller S, Lagrata S, Matharu M. Multiple cranial nerve blocks for the transitional treatment of chronic headaches. Cephalalgia. 2019;39(12):1488-99. https://doi. org/10.1177/0333102419848121

A recent study describing treatment of several chronic primary headaches, including SUNHA, PH and $\mathrm{CH}$, with multiple cranial nerve blocks.

58. Ornello R, Palmisani S, Murphy M, Sacco S, Al-Kaisy A, Lambru G. Sphenopalatine ganglion pulsed radiofrequency for the treatment of refractory chronic SUNCT and SUNA: a prospective case series. Headache. 2020;60:938-45. https://doi.org/10.1111/head. 13788.

59. Levy A, Matharu MS. Short-lasting unilateral neuralgiform headache attacks. Ann Indian Acad Neurol. 2018;21(Suppl 1):S31-s8. https://doi.org/10. 4103/aian.AIAN_356_17.

60. Hassan S, Lagrata S, Levy A, Matharu M, Zrinzo L. Microvascular decompression or neuromodulation in patients with SUNCT and trigeminal neurovascular conflict? Cephalalgia. 2018;38(2):393-8. https://doi. org/10.1177/0333102417735847.

61. Miller S, Watkins L, Matharu M. Long-term follow up of intractable chronic short lasting unilateral neuralgiform headache disorders treated with occipital nerve stimulation. Cephalalgia. 2017;38(5):933-42. https://doi.org/10.1177/0333102417721716

A study of 31 SUNHA patients treated with ONS.

62. Miller S, Akram H, Lagrata S, Hariz M, Zrinzo L, Matharu M. Ventral tegmental area deep brain stimulation in refractory short-lasting unilateral neuralgiform headache attacks. Brain. 2016;139(Pt 10):2631-40. https://doi.org/10.1093/brain/aww204.

63. Leone $M$, Proietti CA. Deep brain stimulation in headache. Cephalalgia. 2016;36(12):1143-8. https:// doi.org/10.1177/0333102415607176.

64. Sjaastad O, Dale I. Evidence for a new (?), treatable headache entity. Headache. 1974;14(2):105-8. https://doi.org/10.1111/j.1526-4610.1974. hed1402105.x.

65. Antonaci F, Sjaastad O. Chronic paroxysmal hemicrania $(\mathrm{CPH})$ : a review of the clinical manifestations. Headache. 1989;29(10):648-56. https://doi. org/10.1111/j.1526-4610.1989.hed2910648.x.

66. Russell D. Chronic paroxysmal hemicrania: severity, duration and time of occurrence of attacks. Cephalalgia. 1984;4(1):53-6. https://doi.org/10. 1046/j.1468-2982.1984.0401053.x.

67. Fuad F, Jones NS. Paroxysmal hemicrania and cluster headache: two discrete entities or is there an overlap? Clin Otolaryngol Allied Sci. 2002;27(6):472-9. https://doi.org/10.1046/j.1365-2273.2002.00615.x. 
68. Sjaastad O, Stovner LJ, Stolt-Nielsen A, Antonaci F, Fredriksen TA. CPH and hemicrania continua: requirements of high indomethacin dosages-an ominous sign? Headache. 1995;35(6):363-7. https://doi. org/10.1111/j.1526-4610.1995.hed3506363.x.

69. Kudrow DB, Kudrow L. Successful aspirin prophylaxis in a child with chronic paroxysmal hemicrania. Headache. 1989;29(5):280-1. https://doi.org/10.1111/j. 1526-4610.1989.hed2905280.x.

70. Mateo I, Pascual J. Coexistence of chronic paroxysmal hemicrania and benign cough headache. Headache. 1999;39(6):437-8. https://doi.org/10.1046/j.15264610.1999.3906437.x.

71. Hannerz J, Ericson K, Bergstrand G. Chronic paroxysmal hemicrania: orbital phlebography and steroid treatment. A case report. Cephalalgia. 1987;7(3):189_ 92. https://doi.org/10.1046/j.1468-2982.1987. 0703189.x.

72. Durko A, Klimek A. Naproxen in the treatment of chronic paroxysmal hsmicrania. Cephalalgia. 1987;7(6_suppl):361-2.

73. Pradalier A, Dry J. Chronic paroxysmal hemicrania. Treatment with indomethacin and diclofenac Therapie. 1984;39(2):185-8.

74. Sjaastad O, Antonaci F. A piroxicam derivative partly effective in chronic paroxysmal hemicrania and hemicrania continua. Headache. 1995;35(9):549-50. https://doi.org/10.1111/j.1526-4610.1995. hed3509549.x.

75. Siow HC. Seasonal episodic paroxysmal hemicrania responding to cyclooxygenase-2 inhibitors.

Cephalalgia. 2004;24(5):414-5. https://doi.org/10. 1111/j.1468-2982.2003.00695.x.

76. Chakravarty A, Mukherjee A, Roy D. Trigeminal autonomic cephalgias and variants: clinical profile in Indian patients. Cephalalgia. 2004;24(10):859-66. https:// doi.org/10.1111/j.1468-2982.2004.00759.x.

77. Lisotto C, Maggioni F, Mainardi F, Zanchin G. Rofecoxib for the treatment of chronic paroxysmal hemicrania. Cephalalgia. 2003;23(4):318-20. https:// doi.org/10.1046/j.1468-2982.2003.00500.x.

78. Coria F, Claveria LE, Jimenez-Jimenez FJ, de Seijas EV. Episodic paroxysmal hemicrania responsive to calcium channel blockers. J Neurol Neurosurg Psychiatry. 1992;55(2):166. https://doi.org/10.1136/jnnp.55.2. 166.

79. Ertem DH. Are repetitive pericranial nerve blocks effective in the management of chronic paroxysmal hemicrania?: a case report. Medicine (Baltimore). 2019;98(31):e16484. https://doi.org/10.1097/md. 0000000000016484.

80. Rossi P, Di Lorenzo G, Faroni J, Sauli E. Seasonal, extratrigeminal, episodic paroxysmal hemicrania successfully treated with single suboccipital steroid injections. Eur J Neurol. 2005;12(11):903-6. https://doi. org/10.1111/j.1468-1331.2005.01106.x.

81. Albertyn J, Barry R, Odendaal CL. Cluster headache and the sympathetic nerve. Headache. 2004;44(2):183-5. https://doi.org/10.1111/j.1526-4610.2004.04038.x.
82.• Miller S, Lagrata S, Watkins L, Matharu M. Occipital nerve stimulation for medically refractory chronic paroxysmal hemicrania. Headache. 2017;57(10):1610-3. https://doi.org/10.1111/head.13187

A study of 16 intractable HC patients treated with ONS.

83. Walcott BP, Bamber NI, Anderson DE. Successful treatment of chronic paroxysmal hemicrania with posterior hypothalamic stimulation: technical case report. Neurosurgery. 2009;65(5):E997; discussion E. https://doi.org/10.1227/01.Neu.0000345937.05186. 73.

84. Medina JL, Diamond S. Cluster headache variant: spectrum of a new headache syndrome. Arch Neurol. 1981;38(11):705-9.

85. Sjaastad O, Spierings EL. "Hemicrania continua": another headache absolutely responsive to indomethacin. Cephalalgia. 1984;4(1):65-70.

86. Peres MF, Silberstein SD, Nahmias S, Shechter AL, Youssef I, Rozen TD, et al. Hemicrania continua is not that rare. Neurology. 2001;57(6):948-51. https://doi. org/10.1212/wnl.57.6.948.

87. Newman LC, Lipton RB, Russell M, Solomon S. Hemicrania continua: attacks may alternate sides. Headache: The Journal of Head and Face Pain. 1992;32(5):237-8.

88. Pasquier F, Leys D, Petit H. "Hemicrania continua": the first bilateral case? Cephalalgia. 1987;7(3):169-70.

89. Bordini C, Antonaci F, Stovner LJ, Schrader H, Sjaastad O. "Hemicrania continua": a clinical review. Headache. 1991;31(1):20-6. https://doi.org/10.1111/j.15264610.1991.hed3101020.x.

90. Matharu MS, Boes CJ, Goadsby PJ. Management of trigeminal autonomic cephalgias and hemicrania continua. Drugs. 2003;63(16):1637-77.

91. Pareja JA, Cuadrado M-L, Fernández-de-las-Peñas C, Montojo T, Álvarez M, López-de-Silanes C. Primary continuous unilateral headaches: a nosologic model for hemicrania continua. Cephalalgia. 2012;32(5):413-8.

92. Da Silva HM, Alcantara M, Bordini C, Speciali J. Strictly unilateral headache reminiscent of hemicrania continua resistant to indomethacin but responsive to gabapentin. Cephalalgia. 2002;22(5):409-10.

93. Porta-Etessam J, Cuadrado M, Rodríguez-Gómez $\mathrm{O}$, García-Ptacek S, Valencia C. Are cox-2 drugs the second line option in indomethacin responsive headaches? J Headache Pain. 2010;11(5):405-7.

94. Matharu M, Bradbury P, Swash M. Hemicrania continua: side alternation and response to topiramate. Cephalalgia. 2006;26(3):341-4.

95. Allena M, Tassorelli C, Sances G, Guaschino E, Sandrini G, Nappi G, et al. Is hemicrania continua a single entity or the association of two headache forms? Considerations from a case report. Headache: The Journal of Head and Face Pain. 2010;50(5):877-81.

96. Prakash S, Rana K. Topiramate as an indomethacinsparing agent in hemicrania continua: a report of 2 cases. Headache. 2019;59(3):444-5. https://doi.org/ 10.1111/head.13490. 
97. Miller S, Correia F, Lagrata S, Matharu MS. OnabotulinumtoxinA for hemicrania continua: open label experience in 9 patients. J Headache Pain. 2015;16:19. https://doi.org/10.1186/s10194-0150502-z.

98. Paul Weyker M, Christopher Webb M, Leena MM. Radiofrequency ablation of the supra-orbital nerve in the treatment algorithm of hemicrania continua. Pain Physician. 2012;15:E719-E24.

99. Androulakis XM, Krebs KA, Ashkenazi A. Hemicrania continua may respond to repetitive sphenopalatine ganglion block: a case report. Headache. 2016;56(3):573-9. https://doi.org/10.1111/head. 12783.

100. Beams JL, Kline MT, Rozen TD. Treatment of hemicrania continua with radiofrequency ablation and long-term follow-up. Cephalalgia. 2015;35(13):1208-13. https://doi.org/10.1177/ 0333102415575726.

101. Miller S, Watkins L, Matharu MS. Treatment of intractable hemicrania continua by occipital nerve stimulation. J Neurol Neurosurg Psychiatry.
2017;88(9):805-6. https://doi.org/10.1136/jnnp2017-315747.

102. Schwedt TJ, Dodick DW, Hentz J, Trentman TL, Zimmerman RS. Occipital nerve stimulation for chronic headache-long-term safety and efficacy. Cephalalgia. 2007;27(2):153-7. https://doi.org/10. 1111/j.1468-2982.2007.01272.x.

103. Burns B, Watkins L, Goadsby PJ. Treatment of hemicrania continua by occipital nerve stimulation with a bion device: long-term follow-up of a crossover study. Lancet Neurol. 2008;7(11):1001-12. https:// doi.org/10.1016/s1474-4422(08)70217-5.

\section{Publisher's Note}

Springer Nature remains neutral with regard to jurisdictional claims in published maps and institutional affiliations. 